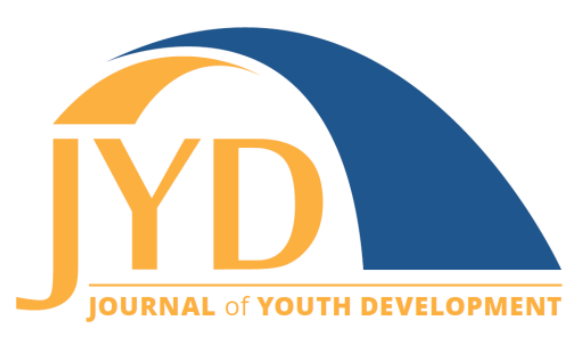

http://jyd. pitt. edu/ | Vol. 14 Issue 3 DOI 10.5195/jyd.2019.780 | ISSN 2325-4017 (online)

\title{
Understanding the Role of Summer Camps in the Learning Landscape: An Exploratory Sequential Study
}

\author{
Dan Richmond \\ University of Utah \\ dan.richmond@utah.edu \\ Jim Sibthorp \\ University of Utah \\ jim.sibthorp@health.utah.edu \\ Cait Wilson \\ University of Utah \\ cait.wilson@utah.edu
}

\begin{abstract}
Summer camp is an important setting within the learning landscape of youth-a landscape that also includes school, sports, arts and music, religious settings, home, and eventually, work. While research on camp outcomes is abundant, practitioners and policymakers have little empirical evidence that summer camp participation offers long-term impact and value. The purpose of this study was to build on existing camp research to identify learning outcomes that are highly attributable to camp participation and to determine whether these outcomes are considered important in everyday life. A second purpose was to identify other settings that may contribute to learning outcomes often associated with camp participation. This study used mixed methods design and involved a national sample of 352 individuals (18-25 years old) who had attended camp for at least 3 weeks in their youth and had not worked at a camp. Alumni reported that the development of independence, perseverance, responsibility, appreciation for differences, and appreciation for being present were camp-related outcomes that were highly attributable to their camp experiences and that these outcomes were also of high importance in daily life. Among all outcomes that were highly attributable to camp, study participants noted that camp was a primary setting for developing affinity for nature, how to live with peers, leisure skills, a willingness to try new things, independence, being present, and empathy and compassion. School and home were primary learning settings for other outcomes. Findings from this study help identify where camp is particularly
\end{abstract}

(c) $\mathrm{EY}_{\mathrm{EY}}$ New articles in this journal are licensed under a Creative Commons Attribution 4.0 License. This journal is published by the University Library System, University of Pittsburgh and is cosponsored by the University of Pittsburgh Press. The Journal of Youth Development is the official peer-reviewed publication of the National Association of Extension 4-H Agents and the National AfterSchool Association. 


\section{Camp's Role in Developing Long-Term Outcomes}

effective in promoting lasting outcomes and areas where camps may need more intentionality and resources.

Key words: summer camp, learning settings, long-term outcomes

\section{Introduction}

People learn, develop, and grow over their lives and across contexts and settings. Some of these settings within the learning landscape are distinct, while others inherently overlap. Settings can support lessons learned elsewhere or may offer contradictions or challenges to previous lessons. Summer camp is an important setting for learning and developing social and emotional learning skills (SEL), with an estimated 14 million youth attending camp in the United States each summer (American Camp Association, 2016). There is a need for more empirical evidence that summer camp participation offers long-term impact and value far beyond the experience, thereby adding to the existing body of literature on camp outcomes (e.g., Bialeschki, Henderson, \& James, 2007; Garst, Gagnon, \& Whittington, 2016; Henderson, Bialeschki, \& James, 2007; Whittington \& Garst, 2018; Wilson \& Sibthorp, 2018). There is also a need for more research that examines how camp contributes to particular SEL outcomes as compared to other learning settings like school, home, sports, and other out-of-school-time activities.

Attaining nationally representative data on long-term learning from summer camp is difficult, largely due to the logistical challenges of accessing a large sample of previous campers' years after attending multiple summer camps in their youth. While an abundance of research has indicated that summer camps have near-term value to youth (e.g., Bialeschki et al., 2007) and studies have demonstrated the potential for long-term impacts with convenience samples of camp alumni (e.g., Garst et al., 2016), research on broader samples years after camp participation remains scarce.

Therefore, the purpose of this study was to examine how former camp participants believe their camp experiences influenced the development of camp-related outcomes and to compare camp to alternative learning settings for these outcomes. Findings will help practitioners to understand both camp's inherent developmental strengths and promising outcomes ripe for intentional focus. 


\section{Background}

Out-of-school-time (OST) learning settings including extracurricular activities, organized sports, arts and music, youth groups, and summer-based activities like camp are important contributors to the growth of social and emotional learning (SEL), identity development, and the supports for positive youth development (Durlak, Weissberg, \& Pachan, 2010; Fredricks \& Eccles, 2006; Putnam, 2015; Vandell, Larson, Mahoney, \& Watts, 2015). Camp can be defined as an organized set of activities led by trained leaders with intentional goals, often held in a unique learning environment like the outdoors (Henderson, Whitaker, Scanlin, \& Thurber, 2007). The inherent nature of camp provides a rich setting for developing positive youth outcomes that support success in school and in life. Due to the wide variety of camp types and camp participants, as well as the difficulty of collecting data from large representative samples, it has been a challenge for researchers to clearly identify the core outcomes of camp as well as the salience of these outcomes in life outside of camp (e.g., Bialeschki et al., 2007; Sibthorp, Browne, \& Bialeschki, 2010; Whittington \& Garst, 2018).

\section{Camp Research on Outcomes}

Research on camp-related outcomes has a long history that dates back to studies in the early $20^{\text {th }}$ century that looked at character development (Henderson, Bialeschki, \& James, 2007) to more recent studies on the near-term impacts of camp participation (approximately a year or less following participation; Bialeschki et al., 2007) and the lasting impacts of camp within a single camp community (Whittington \& Garst, 2018). Indeed, there is a rich literature base on camp outcomes, from studies focused on particular outcomes like sense of community and belonging (e.g., Goodwin, Lieberman, Johnston, \& Leo, 2011; Yuen, Pedlar, \& Mannell, 2005) to studies focused on the unique outcomes of camps working with children with chronic illnesses or disabilities (e.g., Gillard, Witt, \& Watts, 2011; Knapp, Devine, Dawson, \& Piatt, 2015).

The research conducted by Bialeschki and colleagues (2007) and related studies (see Henderson, Whitaker, et al., 2007) included over 5000 campers and their parents from a national sample and examined a wide range of interpersonal and intrapersonal outcomes. Parents reported that their children demonstrated gains in several areas including self-esteem, independence, leadership, social comfort, and peer relationships in pre- to post-camp measures and that gains in these social-emotional learning domains were maintained at a 6-month followup (Bialeschki et al., 2007; Henderson, Whitaker, et al., 2007). 


\section{Camp's Role in Developing Long-Term Outcomes}

Other outcome studies looking at near-term outcomes of camp found outcomes similar to those identified by Bialeschki et al. (2007) with a few additions. For example, research on the camp setting found that camp was particularly good at supporting social connectedness among campers thereby increasing the social capital of participants (Yuen et al., 2005). Research on camps working with youth with disabilities or chronic illnesses have reported outcomes related to social acceptance, relief from stress, and self-efficacy for self-management of their condition (Gillard, Witt, \& Watts, 2011; Knapp et al., 2015).

Retrospective studies on long-term camp outcomes are limited but provide some insight into what lessons from camp may carry over into adulthood. A study involving adults who attended camp as children identified camp-related outcomes within three broad categories: selfdetermined behavior (e.g., confidence, self-efficacy, friendships, initiative, competence), critical thinking, and physical well-being (Garst et al., 2016). Whittington and Garst (2018) examined how camp participation was related to skills associated with college readiness with a sample of alumni. Over $60 \%$ of alumni reported that camp helped them to "a great extent" to develop independence and self-reliance, teamwork skills, self-efficacy, confidence, leadership, selfregulation, and communication skills. Alumni also reported that the camp experience helped shape academic and career interests.

However, many of the studies of long-term camp outcomes have relied on convenience samples that could be overly biased toward camp experiences. For example, Garst and colleagues (Garst et al., 2016; Whittington \& Garst, 2018) invited 350 camps to recruit alumni through email lists and Facebook, resulting in a sample of approximately 427 alumni responses solicited from an unknown number of camps; their sample was $97 \%$ white, $79 \%$ female, and ranged in age from 18 to over 75. More representative samples (e.g., Bialeschki et al., 2007; Henderson, Whitaker, et al., 2007) did not examine the impact of camp participation into adulthood, or even beyond a year removed from camp. In addition, there is a need to understand how well camp-related outcomes apply in adult contexts like college and career and how camp contributes to SEL outcomes as compared to other learning settings (e.g., school, home, church, sports).

Therefore, the purpose of this study was to build on existing camp research to identify learning outcomes that are highly attributable to camp participation and to determine whether these outcomes are considered important in everyday life using a representative national sample. A second but related purpose is to identify other learning settings that may contribute to learning outcomes often associated with camp participation. More specifically, this study sought to answer the following research questions: 


\section{Camp's Role in Developing Long-Term Outcomes}

1. Which camp-related outcomes do camp alumni identify as highly attributable to the camp experience as compared to other camp-related outcomes?

2. Which camp-related outcomes do camp alumni identify as highly important to everyday life as compared to other camp-related outcomes?

3. Among camp alumni who identified given camp-related outcomes as highly attributable to their camp experiences, what was the primary learning setting for that outcomecamp, home, school, work, organized sports, church or some other setting?

Findings from this study may help practitioners recognize the inherent strengths of the camp experience as well as identify promising areas of focus where intentional programming could increase the impact of camp on particular outcomes.

\section{Methods}

This study used a cross-sectional, exploratory sequential mixed methods design to address the research questions and examine the nature of learning from the camp experience. This study design involves qualitative data collection and analysis in the early phase followed by quantitative data collection and analysis (Creswell \& Plano Clark, 2011). For this study the qualitative phase (Phase 1) was used to identify outcomes that might be highly attributable to camp and important in daily life. The qualitative stage then informed instrument creation and quantitative data collection and analysis (Phase 2). Figure 1 describes how an exploratory sequential mixed-methods design was used in this study.

\section{Figure 1. Exploratory Sequential Mixed Methods Design in This Study}

- Qualitative Data Collection and Analysis

-Interviews with camp alumni about camp outcomes

-Analysis and coding of interviews

Phase 1

\section{Phase 2}

- Quantitative Data Collection and Analysis

-Instrument creation and testing

- Survey administration

-Analysis of survey data 


\section{Phase 1 Methods}

Phase 1 involved 64 individuals between the ages of 16 and $23(M=18)$ who attended at least 3 weeks of camp in the United States during their youth. The sample included alumni from 22 camps from across the United States with the intention of representing the broad range of camps accredited by the American Camp Association. A stratified sample was selected from a list of volunteers collected by the American Camp Association to include a balance of alumni from residential overnight camps, day camps, religious affiliated camps, specialized camps for participants with particular needs (e.g., medical), and camps serving low-income participants. The sample was 78\% female, 72\% white, 9\% African American, 9\% multi-racial, 5\% Hispanic or Latinx, and 5\% undisclosed. Study participants had applied to work at camps but had not yet worked at a camp when they were interviewed. See Wilson, Akiva, Sibthorp, \& Browne, 2019 for additional details on the methods and results of Phase 1.

Participants in Phase 1 were interviewed by phone using a semi-structured format during the spring of 2017. Interviewers asked participants about what they learned at camp and how they were able to apply areas of learning at camp to other areas of their lives. Follow-up questions allowed interviewers to gain greater insight into responses (Charmaz, 2014). Each interview took approximately 25 minutes to conduct.

Interviews were recorded, transcribed, and then coded independently by two researchers using descriptive, axial, and focused coding that identified themes and connections among these themes (Miles, Huberman, \& Saldaña, 2014). Two researchers worked together to identify, refine, and verify themes. This coding resulted in 18 outcome areas associated with camp participation (see Table 1). 
Table 1. Descriptions of Learning Outcomes Identified Through Qualitative Coding of Interviews

\begin{tabular}{|l|l|}
\hline Learning outcome & Description \\
\hline Willingness to try new things & Attitude of receptivity to new ideas and experiences. \\
\hline Affinity for nature & Appreciation for the natural world and nature. \\
\hline Independence & Ability to function independently without reliance on family. \\
\hline Leisure skills & Ability to participate in sport and/or recreation activities. \\
\hline Perseverance & Ability to persevere in the face of challenges. \\
\hline Appreciation for differences & Appreciation for different people and perspectives. \\
\hline Teamwork & Ability to work as part of a team on a task. \\
\hline Being present & An appreciation for being present in the moment, free of distractions, \\
\hline Responsibility & interacting with the world and others in an authentic way. \\
\hline Leadership & Willingness to be responsible for own behaviors. \\
\hline Relationship skills & Ability to lead a group of peers to complete a task. \\
\hline How to live with peers & Ability to form relationships with others. \\
\hline Self-confidence & Ability to live in close quarters with peers. \\
\hline Empathy and compassion & Confidence in abilities to be successful. \\
\hline Emotion regulation & Ability to empathize with others. \\
\hline Organization & Ability to control emotions. \\
\hline Self-identity & Ability to be organized. \\
\hline Career orientation & Understanding of who I am and how I want to live my life. \\
\hline Understanding of what to do for a career or in college. \\
\hline
\end{tabular}

\section{Phase 2 Methods}

Following Phase 1 of this study, a survey instrument was designed. For Phase 2, a panel of youth development experts reviewed the retrospective questionnaire for content validity, ensuring the questionnaire accurately measured the intended constructs (i.e., the 18 learning outcomes from camp). The questionnaire was then piloted using 173 undergraduate students at a large public university in the United States. These participants offered feedback on question clarity and response options. Researchers reviewed pilot data to ensure variation and overall data quality. The questionnaire was further revised to improve the clarity of questions and response scales. 


\section{Camp's Role in Developing Long-Term Outcomes}

The final instrument consisted of questions in three main areas: (a) a 10-point rating scale assessing the role of camp in developing these outcomes, (b) a 10-point scale assessing the importance of learning outcomes in everyday life, and (c) a section where participants identified the primary setting for developing each outcome (camp, home, school, work, organized sports, church, or other). In addition to the closed-ended survey data reported in this paper, participants completed a series of screener questions (e.g., weeks at camp and age) and provided qualitative responses to six open-ended questions; the qualitative responses were analyzed separately to inform different research questions. See Table 2 for example items for the data examined in this paper.

Table 2. Sample Items From Survey Instrument

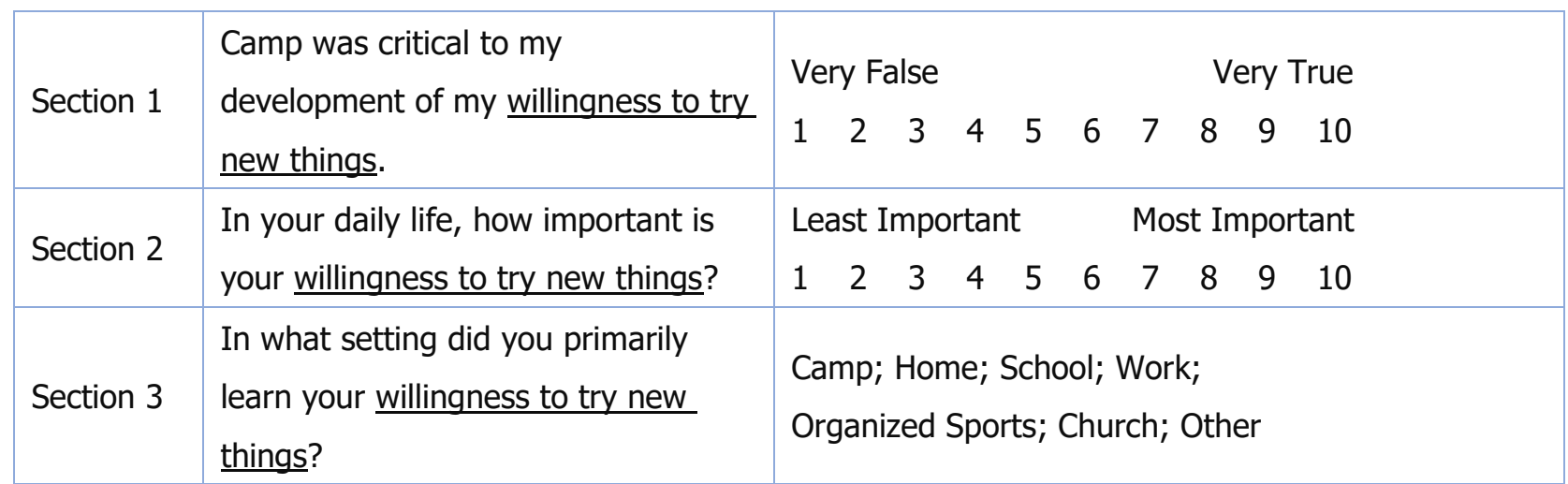

Note. Similar questions were created for each of the learning outcomes. Additionally, if participants indicated a 9 or 10 on a 10-point scale for the questions in section 1 , then conditional logic was used to display a corresponding question in section 3 about the primary setting in which that outcome was learned.

\section{Sampling Procedures}

Once the instrument was finalized, participants were recruited through an online panel provided by the research firm Qualtrics. An online panel is a database of individuals willing to participate in survey research if selected for the study (Callegaro et al., 2014). To participate in this study, respondents had to meet specific inclusion criteria in regard to age (i.e., 18-25 years old), camp participation (i.e., attended camp in their youth for at least three weeks in the United States), and work history (i.e., did not work at camp). Individuals who met the inclusion criteria subsequently filled out the questionnaire. Quotas were established through Qualtrics to ensure equal representation of male and female respondents. Participants were awarded an incentive for filling out the survey after their responses were verified for quality. 


\section{Camp's Role in Developing Long-Term Outcomes}

\section{Data Analysis}

The research team analyzed the data using descriptive statistics. First, means were calculated in each outcome area for camp's role in development and importance in everyday life. Second, means were then plotted along two axes. Two cut-points were established for each dimension: one from the grand mean of the importance of outcomes to everyday life ( $x$-axis) and the other from the grand mean of the role of camp in the development of the outcome ( $y$-axis). This approach is similar to a importance-performance analysis used in a variety of research areas that helps identify areas of strength and opportunities for improvement in a given organization or industry (Martilla \& James, 1977). This process resulted in four quadrants:

- Quadrant I: Outcomes highly attributable to camp and of high importance in daily life.

- Quadrant II: Outcomes less attributable to camp and of high importance in daily life.

- Quadrant III: Outcomes highly attributable to camp and of less importance in daily life.

- Quadrant IV: Outcomes less attributable to camp and of less importance in daily life. Finally, responses that rated particular outcomes as highly attributable to camp (scores of 9 or 10) were analyzed to identify the primary learning setting for that outcome.

\section{Results}

The study included 352 usable responses from participants who had attended camp for at least 3 weeks as a camper and had not worked at a camp. Fifty-two percent identified as female and $1.1 \%$ identifying as gender non-conforming. Approximately $62.8 \%$ identified as White, $14.2 \%$ as African American, 9.4\% were Hispanic or Latinx, 9.1\% as multi-racial, 3.4\% as Asian and $1.1 \%$ as other. For comparison, according to the U.S. Census Bureau (2019), the United States population in 2018 was 76.5\% White, 13.4\% African American, 18.3\% Hispanic or Latinx, 2.7\% multi-racial, 5.9\% Asian, 1.3\% American Indian or Alaska Native, and 0.2\% Native Hawaiian or other Pacific Islander. Participants ranged from 18 to 25 (median age: 21), 99\% held a high school degree and $81 \%$ had some college or more. On average, participants were approximately seven years removed from their last, or more recent, camp experience. When reporting on their last summer of camp experiences, $31 \%$ of respondents reported that they attended day camp, 43\% had attended overnight camp, and 26\% had attended both day and overnight camps. Among respondents, $13.4 \%$ reported that they participated in a counselor-intraining (CIT) or leader-in-training (LIT) program as campers. 
Quadrant I: Outcomes Highly Attributable to Camp and of High Importance in Daily Life

Figure 2 presents how respondents rated the role of camp in the development of an outcome and the importance of the outcome in daily life. Participants identified appreciation for differences, being present, independence, perseverance, and responsibility as outcomes highly attributable to camp and highly important to their daily lives (see Quadrant I of Figure 2). The means for each of these outcomes were higher than the average of all means (grand means) for both the role of camp and importance in daily life.

Figure 2. The Role of Camp in Developing Transferable Learning Outcomes

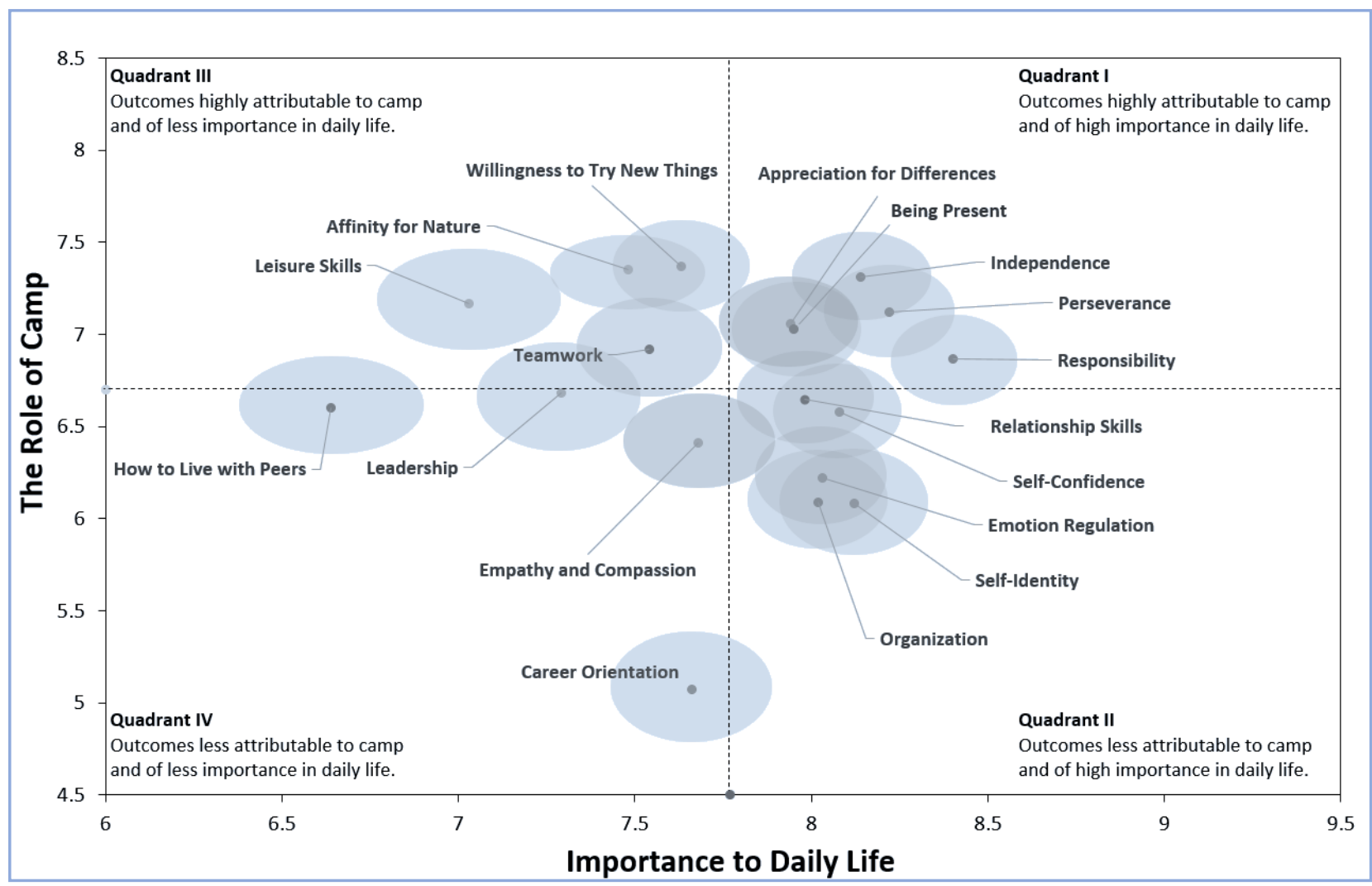

Notes. The location of each learning outcome represents its mean for whether the outcome was highly attributable to camp ( 1 = very false, 10 = very true) and the mean of whether the outcome was considered important in everyday life (1 = least important, 10 = most important). The cut point on the $x$-axis is the grand mean of all outcomes for importance to daily life and the cut point on the $y$-axis is the grand mean of all outcomes for the role of camp. These cut points are used for relative comparisons. The translucent oval surrounding each point on the scatterplot represents the confidence interval for each learning outcome (95\%). If a confidence interval for any outcome includes the mean of another outcome, the means are not statistically different. 
Camp's Role in Developing Long-Term Outcomes

Quadrant II: Outcomes Less Attributable to Camp and of High Importance in Daily Life

Outcomes less attributable to camp but still important to daily life (Quadrant II) included relationship skills, self-confidence, emotion regulation, self-identity, and organization. However, an examination of the confidence intervals indicates that both relationship skills and selfconfidence could arguably be categorized into Quadrant I.

\section{Quadrant III: Outcomes Highly Attributable to Camp and of Less Importance in} Daily Life

Leisure skills, affinity for nature, willingness to try new things, and teamwork fell into Quadrant III. These outcomes were highly attributable to camp but less important to daily life as compared to other outcomes.

\section{Quadrant IV: Outcomes Less Attributable to Camp and of Less Importance in Daily} Life

Outcomes in Quadrant IV included how to live with peers, leadership, empathy and compassion, and career orientation. These outcomes had means indicating that they were less attributable to camp and less important to their daily lives than other measured outcomes. Examination of confidence intervals in this quadrant show that how to live with peers and leadership could be categorized into Quadrant III and empathy and compassion and career orientation could be categorized into Quadrant II.

\section{Caveats on Quadrant Classifications}

As the cases above illustrate, an examination of the confidence intervals makes a definitive classification of some outcomes difficult. It is also important to note that the grand means for each dimension serve as the cut point along each axis. The cut point on the $X$-axis is the grand mean of all outcomes for importance to daily life and the cut point on the Y-axis is the grand mean of all outcomes for the role of camp. These cut points are used for relative comparisons. Because these cut points are dependent on the outcomes included and measured in the study, they should be interpreted collectively with the outcome-specific means and confidence intervals. Notably, as all the reported means exceed the scale midpoint of 5.5 (except for career orientation and the role of camp), participants reported both some role of camp in developing 
Journal of Youth Development | http://jyd.pitt.edu/ | Vol. 14 Issue 3 DOI 10.5195/jyd.2019.780 Camp's Role in Developing Long-Term Outcomes

all the outcomes and some importance of all the outcomes in daily life. Table 3 summarizes the means of each learning outcome along each dimension.

Table 3. Means and Confidence Intervals of Learning Outcomes

\begin{tabular}{|c|c|c|c|c|c|c|}
\hline \multirow[b]{3}{*}{ Learning outcomes } & \multicolumn{3}{|c|}{ Attributable to camp } & \multicolumn{3}{|c|}{ Importance in daily life } \\
\hline & \multirow[b]{2}{*}{$M$} & \multicolumn{2}{|c|}{$95 \%$ CI } & \multirow[b]{2}{*}{$M$} & \multicolumn{2}{|c|}{$95 \%$ CI } \\
\hline & & Lower & Upper & & Lower & Upper \\
\hline Willingness to try new things & 7.37 & 7.12 & 7.62 & 7.63 & 7.44 & 7.83 \\
\hline Affinity for nature & 7.35 & 7.08 & 7.62 & 7.48 & 7.26 & 7.70 \\
\hline Independence & 7.31 & 7.05 & 7.56 & 8.14 & 7.94 & 8.34 \\
\hline Leisure skills & 7.17 & 6.89 & 7.46 & 7.03 & 6.77 & 7.29 \\
\hline Perseverance & 7.12 & 6.86 & 7.37 & 8.22 & 8.04 & 8.41 \\
\hline Appreciation for differences & 7.06 & 6.81 & 7.32 & 7.93 & 7.74 & 8.13 \\
\hline Being present & 7.02 & 6.76 & 7.29 & 7.95 & 7.77 & 8.14 \\
\hline Teamwork & 6.92 & 6.65 & 7.19 & 7.54 & 7.34 & 7.75 \\
\hline Responsibility & 6.86 & 6.61 & 7.13 & 8.40 & 8.22 & 8.58 \\
\hline Leadership & 6.67 & 6.40 & 6.95 & 7.28 & 7.05 & 7.52 \\
\hline Relationship skills & 6.65 & 6.39 & 6.91 & 7.98 & 7.79 & 8.18 \\
\hline How to live with peers & 6.59 & 6.32 & 6.88 & 6.64 & 6.38 & 6.91 \\
\hline Self-confidence & 6.58 & 6.31 & 6.85 & 8.08 & 7.89 & 8.27 \\
\hline Empathy and compassion & 6.40 & 6.15 & 6.67 & 7.68 & 7.47 & 7.90 \\
\hline Emotion regulation & 6.22 & 5.95 & 6.49 & 8.02 & 7.84 & 8.22 \\
\hline Organization & 6.09 & 5.82 & 6.37 & 8.02 & 7.82 & 8.22 \\
\hline Self-Identity & 6.08 & 5.79 & 6.37 & 8.11 & 7.91 & 8.33 \\
\hline Career orientation & 5.06 & 4.76 & 5.37 & 7.65 & 7.43 & 7.89 \\
\hline Grand mean & 6.70 & & & 7.77 & & \\
\hline
\end{tabular}

Note. Table summarizes the means of each learning outcome along with the upper and lower bounds of a $95 \%$ confidence interval. The grand means for each dimension were used as cut points for plotting means in Figure 2.

\section{Primary Learning Settings for Camp-Related Outcomes}

Among participants who rated camp as highly critical to the development of particular outcomes (scores of 9 or 10), camp was the primary setting for the outcomes affinity for nature, how to 
Camp's Role in Developing Long-Term Outcomes

live with peers, leisure skills, a willingness to try new things, independence, being present, and empathy and compassion (see Table 4).

Table 4. Primary Learning Settings for Camp-Related Outcomes

\begin{tabular}{|l|l|l|l|l|l|l|l|l|}
\hline Outcome & Camp & Home & School & Work & Sports & Church & Other & Total \\
\hline Affinity for nature & $26.7 \%$ & $6.0 \%$ & $1.1 \%$ & $1.4 \%$ & $0.6 \%$ & $1.7 \%$ & $1.1 \%$ & $38.6 \%$ \\
\hline How to live with peers & $15.6 \%$ & $3.4 \%$ & $4.5 \%$ & $1.7 \%$ & $0.9 \%$ & $0.6 \%$ & $0.3 \%$ & $27.0 \%$ \\
\hline Leisure skills & $15.1 \%$ & $3.1 \%$ & $7.7 \%$ & $0.9 \%$ & $10.2 \%$ & $0.6 \%$ & $0.0 \%$ & $37.6 \%$ \\
\hline Willingness to try new things & $14.5 \%$ & $6.8 \%$ & $7.7 \%$ & $1.7 \%$ & $2.3 \%$ & $1.7 \%$ & $1.1 \%$ & $35.8 \%$ \\
\hline Independence & $15.1 \%$ & $4.0 \%$ & $8.5 \%$ & $6.0 \%$ & $2.3 \%$ & $0.9 \%$ & $0.6 \%$ & $37.4 \%$ \\
\hline Being Present & $11.9 \%$ & $4.5 \%$ & $3.7 \%$ & $1.7 \%$ & $3.4 \%$ & $3.7 \%$ & $2.0 \%$ & $30.9 \%$ \\
\hline Empathy and compassion & $6.5 \%$ & $2.6 \%$ & $6.3 \%$ & $2.0 \%$ & $1.1 \%$ & $3.1 \%$ & $0.0 \%$ & $21.6 \%$ \\
\hline Appreciation for differences & $9.1 \%$ & $1.7 \%$ & $11.1 \%$ & $3.1 \%$ & $1.1 \%$ & $3.1 \%$ & $1.1 \%$ & $30.3 \%$ \\
\hline Leadership & $7.1 \%$ & $0.9 \%$ & $7.7 \%$ & $4.8 \%$ & $2.6 \%$ & $1.4 \%$ & $0.9 \%$ & $25.4 \%$ \\
\hline Perseverance & $9.1 \%$ & $2.3 \%$ & $12.5 \%$ & $3.7 \%$ & $5.1 \%$ & $1.1 \%$ & $0.8 \%$ & $34.6 \%$ \\
\hline Teamwork & $8.2 \%$ & $0.3 \%$ & $11.4 \%$ & $2.8 \%$ & $6.0 \%$ & $1.1 \%$ & $0.3 \%$ & $30.1 \%$ \\
\hline Self-Identity & $5.1 \%$ & $6.5 \%$ & $4.0 \%$ & $2.0 \%$ & $1.1 \%$ & $2.3 \%$ & $0.6 \%$ & $21.6 \%$ \\
\hline Relationship skills & $5.4 \%$ & $1.7 \%$ & $11.1 \%$ & $1.1 \%$ & $2.6 \%$ & $1.1 \%$ & $0.0 \%$ & $23.0 \%$ \\
\hline Emotion regulation & $4.3 \%$ & $5.4 \%$ & $5.1 \%$ & $1.4 \%$ & $2.6 \%$ & $1.1 \%$ & $0.0 \%$ & $19.9 \%$ \\
\hline Self-confidence & $4.5 \%$ & $5.7 \%$ & $6.5 \%$ & $4.3 \%$ & $2.8 \%$ & $1.4 \%$ & $0.3 \%$ & $25.5 \%$ \\
\hline Career orientation & $2.6 \%$ & $2.3 \%$ & $7.7 \%$ & $1.4 \%$ & $0.6 \%$ & $0.0 \%$ & $0.6 \%$ & $15.2 \%$ \\
\hline Organization & $3.1 \%$ & $4.8 \%$ & $10.5 \%$ & $2.0 \%$ & $1.4 \%$ & $0.0 \%$ & $0.0 \%$ & $21.8 \%$ \\
\hline Responsibility & $3.7 \%$ & $11.6 \%$ & $6.3 \%$ & $3.4 \%$ & $1.7 \%$ & $0.9 \%$ & $0.6 \%$ & $28.2 \%$ \\
\hline
\end{tabular}

Note. The total column shows the percentage of respondents who reported that development of that outcome was highly attributable to camp ( 9 or $10 ; N=352$ ). These respondents were then asked to identify the primary learning setting for that outcome. Cells with a dark blue background indicate the learning setting with the highest frequency for a given outcome. Cells with a light blue background indicate other notable learning settings.

This same subset of respondents identified school as the primary setting for developing an appreciation for differences, leadership, perseverance, teamwork, relationship skills, selfconfidence, career orientation, and organization-even though participants initially rated camp as highly important to the development of these outcomes (9 or 10 ). Home was the primary setting where respondents developed self-identity, emotion regulation, and responsibility. Respondents also reported that work was also an important setting for learning independence, 


\section{Camp's Role in Developing Long-Term Outcomes}

appreciation for differences, leadership, perseverance, self-confidence and responsibility. Sports was an important setting for learning leadership skills, being present, perseverance and teamwork. Church was recognized as another important setting where respondents learned empathy and compassion, an appreciation for differences, and an appreciation for being present.

\section{Discussion}

The purpose of this study was to examine what former camp participants believed they learned at summer camp and identify which of these outcomes remained most salient into adulthood. The study also examined the role of camp experiences in development of key learning outcomes as compared to other learning settings. Findings show that camp was especially effective in promoting an appreciation for differences, being present, independence, perseverance, and responsibility, and that these outcomes were highly important in daily life. Camp was also a key learning setting for developing leisure skills, affinity for nature, willingness to try new things, and teamwork yet these outcomes were of less importance to daily life, though still important. Among respondents who rated outcomes highly attributable to camp, findings support that camp was the primary learning setting for developing affinity for nature, leisure skills, willingness to try new things, independence, and an appreciation for being present as compared to home, school, and other settings.

\section{Contextualizing Outcomes Highly Attributable to Camp}

Existing research has identified similar outcomes of camp participation, noting that camp is a setting where children and adolescents can develop important interpersonal and intrapersonal competencies (cf. Bialeschki et al., 2007; Duerden et al., 2014; Garst \& Ozier, 2015). This study provides additional insight as to how well camp outcomes transfer beyond camp while recognizing the contributions of other learning settings.

Intrapersonal skills like independence, perseverance, and responsibility have appeared consistently in camp literature as key outcomes of the camp experience, as has self-confidence which was near the cut point of outcomes deemed highly attributable to camp (Henderson, Whitaker, et al., 2007; Sibthorp et al., 2010; Whittington \& Garst, 2018). One common aspect of camp-being away from home and family in a new social milieu-appears to support the development of these outcomes effectively. Indeed, the social norms of many camps set the expectation of personal responsibility and independence while providing a supportive 


\section{Camp's Role in Developing Long-Term Outcomes}

environment to help youth manage difficulties like homesickness, interpersonal conflict, and other challenges and build general self-efficacy and confidence (Henderson, Bialeschki, Scanlin, et al., 2007). The findings from this study support the assertion that these skills are highly attributable to camp experiences and valuable later in life (see also: Olsen, Powell, Garst, \& Bixler, 2018).

Camp has also been associated with the development of key interpersonal competencies like relationship skills and an appreciation for differences (Bialeschki et al., 2007; Garst \& Ozier, 2015). Those findings are supported in this study. Camps provide opportunities for young people to encounter others-both campers and camp staff-who may be unlike people in their lives back home. This may be in terms of race, ethnicity, ability, beliefs, or experiences. Other studies have proposed that camp provides a "common ground" for individuals from different backgrounds to make deep connections (e.g., Yuen et al., 2005).

Making deep and authentic connections with others is closely related to another camp outcome identified as important to daily life, an appreciation for being present. Being present seems understandable as one of camp's main objectives is to engage participants deeply through play, novel activities, and meaningful connections with others (Duerden et al., 2014; Henderson, Bialeschki, \& James, 2007). There are elements of the camp experience that support the ability to live in the moment, including being away from technology and the stresses of school and home life. Other studies have found that camp-like contexts support feelings of being present (Richmond, Sibthorp, Gookin, Annarella, \& Ferri, 2018), mindfulness (Gillard, Roark, Nyaga, \& Bialeschki, 2011), and provide opportunities for authentic interactions with others (Goodwin et al., 2011). Future studies may want to examine how camp experiences help participants seek out opportunities to disconnect from everyday life and live in the moment for the benefit of personal well-being.

Camp was also identified as a highly attributable learning setting for developing teamwork, a willingness to try new things, an affinity for nature, and specific leisure skills such as hiking, climbing, or sports. Again, these outcomes that have been tied to the camp experience in other research studies and this study support those findings (cf. Bialeschki et al., 2007; Henderson, Bialeschki, \& James, 2007; Whittington \& Garst, 2018; Yuen et al., 2005). However, this study found that these outcomes were less important to daily life relative to other outcomes. This may be because there are fewer opportunities to apply and practice these skills in everyday settings such as work, life, or school. It seems that camp is a ripe setting to connect with nature, try new things, work with others on a team, and develop specific leisure skills. Further, 


\section{Camp's Role in Developing Long-Term Outcomes}

it is important to note that just because these outcomes were reported as less important to daily life as compared to other outcomes in this study, it does not mean that they are unimportant. Participants rated each of these outcomes at a 7 or higher on a scale of 10 for importance to daily life.

\section{Promising Areas of Focus for Camps}

For this study, the outcomes that were identified as highly attributable to camp and of high importance to daily life could be considered the most useful outcomes that camps, broadly speaking, inherently promote. While camps should continue to craft intentional programming and situations to promote these outcomes, it may be best to focus on programming to develop other outcomes central to the goals of individual camps, particularly those that were identified as important to daily life but less attributable to camps. In this study, these outcomes included organization, self-identity, emotion regulation, and to a lesser degree, self-confidence and relationship skills. Camps that want to increase their impact on these outcomes might benefit from having intentionally designed programs that support targeted outcome development. For example, organization was identified as a skill important in daily life, but camps may or may not explicitly emphasize organization at camp. From the findings in this study, organization is not a skill supported inherently by camp participation, at least as compared to other outcomes. Skillbuilding at camp, whether it be emotion regulation, relationship skills or organization, needs to be supported through curriculum, activities, and opportunities to practice to see results (Bialeschki et al., 2007; Duerden \& Witt, 2010; Gestsdottir \& Lerner, 2008).

Youth-serving organizations like camps should use self-assessment tools to guide programming and program improvement-tools that identify which outcomes should be targeted and how those outcomes can be achieved. Eccles and Gootman (2002) provide some guidance as to the program features that support positive youth development: physical and psychological safety, appropriate structure, supportive relationships, opportunities to belong, positive social norms, support for efficacy and mattering, opportunities for skill building, and integration of family, school, and community efforts. Camp leaders can then consider the intended outcomes of programming to identify necessary program elements, short-term and long-term outcomes, data sources and performance measures to establish a "theory of change" (American Camp Association, 2007; McLaughlin \& Jordan, 2010). A theory of change "is a way to explain the often unwritten or unconscious assumptions about the design and operation of camp programs" (American Camp Association, 2007, p. 19). This involves articulating how program goals and outcomes will be achieved and recognizing the various mechanisms that are involved between 


\section{Camp's Role in Developing Long-Term Outcomes}

program delivery and the development of outcomes (Brousselle \& Champagne, 2011). A theory of change can then inform a logic model which can guide both the program implementation and program evaluation process (Wells \& Arthur-Banning, 2008). By using theories of change and logic models, camp leaders can target specific outcomes more strategically and make necessary adjustments to programming along the way.

\section{Recognizing the Vast Learning Landscape}

A distinct feature of this study was that it sought to understand how camp compared to other learning settings for these outcomes. Again, among those who rated outcomes as highly attributable to camp, camp was also identified as the primary learning setting for developing affinity for nature, leisure skills, willingness to try new things, independence, and an appreciation for being present. Notably, over a quarter of all respondents said that camp was a primary and essential setting where they developed an affinity for nature. This aligns with previous research on camp that noted camp's role in affording youth opportunities to explore and appreciate the natural world - opportunities that may not be as plentiful in other learning spaces (Henderson, Whitaker, et al., 2007). Perhaps more interestingly, even among those participants who rated camp as a highly important learning setting for an outcome, many still identified other learning settings like home, school, and sports as the primary learning setting for that same outcome. For example, school was identified as primary learning setting for appreciating differences, perseverance, teamwork, relationship, skills, and organization, among others. Home was a primary learning setting for responsibility, emotion regulation and selfidentity. This may not be a surprise as research on youth development identifies school and home as the central learning spaces for these outcomes as this is where youth spend the most time and have the most time to develop skills, their sense of identity, and future goals (Duckworth \& Carlson, 2013; Nagaoka, Farrington, Ehrlich, \& Heath, 2015; Shechtman, DeBarger, Dornsife, Rosier, \& Yarnall, 2013). Camp can play a role in the development of these outcomes by providing a space for exploration and practice, but camp's influence may be limited in comparison to other learning settings.

Findings from this study reflect educational frameworks that recognize the complex interaction of factors within the learning landscape that influence youth development (cf. Bronfenbrenner \& Morris, 2006; Nagaoka et al., 2015). While camp plays an important role for many outcomes, the influence of other learning contexts like home and school must be considered. Camp can be one of many positive developmental experiences that contribute to a healthy transition to adulthood. 
By understanding the long-term impacts of camp and the relative importance of outcomes on daily life, practitioners may gain some insight as to which outcomes might need additional attention. There are some things that camp does inherently well while other outcomes may require more intentionality, resources, and time to yield lasting results. This is not to say that program staff should ignore the development of other skills as many of the outcomes from this study are intertwined. For example, organization and emotional regulation are integral to the development of independence, perseverance, and responsibility.

Future research may want to build on this retrospective study by using longitudinal designs to better understand how camp-related outcomes develop over time. This may involve identifying underlying learning mechanisms and how they contribute to specific learning outcomes. Camprelated research may also want to consider incorporating more ecological development approaches to understand more fully the role of camp in personal development within a system of other dynamic learning settings like home, school, work, and other contexts (see Nagaoka et al., 2015). Finally, future research could compare camp types and camp characteristics and their influence on valued and useful outcomes.

\section{Limitations}

This study had several limitations. First, while the panel sample provided a more diverse group of respondents with less inherent positive biases toward camp than a sample that may have included current camp staff, it included study participants who went to a variety of camps, from traditional residential camps and day camps to specialized camps. Grouping all these camp types together allowed the researchers to identify common long-term outcomes of camp, but such an approach may not accurately represent the unique strengths and weaknesses of a particular camp. Second, when comparing learning settings for camp-related outcomes, this study collected data only from study participants who reported that camp was especially impactful on a particular outcome. While this shortened the length of the survey to stave off survey fatigue, it provided less robust data about the relative importance of the settings. Third, the cross-sectional retrospective study is prone to some bias including non-response and recall bias that can affect findings. Finally, the generalizability of findings to the general population of camp participants is unclear, though findings do generalize back to existing theory and research. 


\section{Camp's Role in Developing Long-Term Outcomes}

\section{Conclusion}

This study reaffirms that camp is an important learning setting and that many of the outcomes associated with camp participation last into adulthood. Perhaps more importantly, this study identified outcomes that were both highly attributable to camp and highly important in the daily lives of camp alumni as compared to other areas of learning. Camp appears to be especially good at fostering the development of prized outcomes such as an appreciation for differences, being present, independence, perseverance, and responsibility. This reinforces other research (Bialeschki et al., 2007; Henderson, Whitaker, et al., 2007; Whittington \& Garst, 2018) that identified that the inherent nature of camp-a novel environment away from home with new social groups, norms, and customs-is one that offers a fertile setting for learning and personal growth among youth.

Yet there is more research to be done on the lasting influence of camp and the role of other learning settings. This study revealed that camp contributes to the development of important and useful outcomes while also acknowledging the central role of other learning settings like home, work, school, sports, and church. The developmental trajectories of youth are complex and multifaceted with key learning experiences occurring across many different settings. Future research will need to examine how these experiences and learning settings interact over time to contribute to the development of outcomes associated with camp.

\section{References}

American Camp Association. (2007). Creating positive youth outcomes. Monterey, CA: Healthy Learning. American Camp Association. (2016). Camp sites, facilities, and program report. Bloomington, Indiana. Bialeschki, M. D., Henderson, K. A., \& James, P. A. (2007). Camp experiences and developmental outcomes for youth. Child and Adolescent Psychiatric Clinics of North America, 16(4), 769-788. doi:10.1016/j.chc.2007.05.011

Bronfenbrenner, U., \& Morris, P. A. (2006). The bioecological model of human development. In R. M. Lerner \& W. Damon (Eds.), Handbook of child psychology volume 1: Theoretical models of human development ( $6^{\text {th }}$ ed., pp. 793-828). Hoboken, NJ: John Wiley \& Sons.

Brousselle, A., \& Champagne, F. (2011). Program theory evaluation: Logic analysis. Evaluation and Program Planning, 34(1), 69-78. doi:10.1016/j.evalprogplan.2010.04.001

Callegaro, M., Baker, R. P., Bethlehem, J., Göritz, A. S., Krosnick, J. A., \& Lavrakas, P. J. (Eds.). (2014). Online panel research: $A$ data quality perspective. San Francisco, CA.

Charmaz, K. (2014). Constructing grounded theory ( $2^{\text {nd }}$ ed.). Thousand Oaks, CA: SAGE. 
Journal of Youth Development | http://jyd.pitt.edu/ | Vol. 14 Issue 3 DOI 10.5195/jyd.2019.780

\section{Camp's Role in Developing Long-Term Outcomes}

Creswell, J. W., \& Plano Clark, V. L. (2011). Choosing a mixed methods design. In J. W. Creswell \& V. L. Plano-Clark (Eds.), Designing and conducting mixed methods research (2 ${ }^{\text {nd }}$ ed., pp. 53-106). Thousand Oaks, CA: Sage.

Duckworth, A. L., \& Carlson, S. (2013). Self-regulation and school success. In B. W. Sokol, F. M. E. Grouzet, \& U. Müller (Eds.), Self-regulation and autonomy: Social and developmental dimensions of human conduct (pp. 208-230). Cambridge, UK: Cambridge University Press.

Duerden, M. D., \& Witt, P. A. (2010). An ecological systems theory perspective on youth programming. Journal of Park and Recreation Administration, 28(2), 108-120.

Duerden, M. D., Witt, P., Garst, B. A., Bialeschki, D., Schwarzlose, T., \& Norton, K. (2014). The impact of camp employment on the workforce development of emerging adults. Journal of Park \& Recreation Administration, 32(1), 26-44.

Durlak, J. A., Weissberg, R. P., \& Pachan, M. (2010). A meta-analysis of after-school programs that seek to promote personal and social skills in children and adolescents. American Journal of Community Psychology, 45, 294-309. doi:10.1007/s10464-010-9300-6

Eccles, J., \& Gootman, J. A. (2002). Community programs to promote youth development. National Academies Press. doi:org/10.17226/10022

Fredricks, J. A., \& Eccles, J. S. (2006). Is extracurricular participation associated with beneficial outcomes? Concurrent and longitudinal relations. Developmental Psychology, 42(4), 698-713. doi:10.1037/0012-1649.42.4.698

Garst, B. A., Gagnon, R. J., \& Whittington, A. (2016). A closer look at the camp experience: Examining relationships between life skills, elements of positive youth development, and antecedents of change among camp alumni. Journal of Outdoor Recreation, Education, and Leadership, 8(2), 180-199.

Garst, B. A., \& Ozier, L. W. (2015). Enhancing youth outcomes and organizational practices through a camp-based reading program. Journal of Experiential Education, 38(4), 324-338. doi:10.1177/1053825915578914

Gestsdottir, S., \& Lerner, R. M. (2008). Positive development in adolescence: The development and role of intentional self-regulation. Human Development, 51(3), 202-224. doi:org/10.1159/000135757

Gillard, A., Roark, M. F., Nyaga, L. R. K., \& Bialeschki, M. D. (2011). Measuring mindfulness in summer camp staff. Journal of Experiential Education, 34(1), 87-95. doi:10.1177/105382591103400107

Gillard, A., Witt, P. A., \& Watts, C. E. (2011). Outcomes and processes at a camp for youth with HIV/AIDS. Qualitative Health Research, 21(11), 1508-1526. doi:10.1177/1049732311413907

Goodwin, D. L., Lieberman, L. J., Johnston, K., \& Leo, J. (2011). Connecting through summer camp: Youth with visual impairments find a sense of community. Adapted Physical Education Quarterly, 28, 40-55. 
Journal of Youth Development | http://jyd.pitt.edu/ | Vol. 14 Issue 3 DOI 10.5195/jyd.2019.780

Camp's Role in Developing Long-Term Outcomes

Henderson, K. A., Bialeschki, M. D., \& James, P. A. (2007). Overview of camp research. Child and Adolescent Psychiatric Clinics of North America, 16(4), 755-767. doi:10.1016/j.chc.2007.05.010

Henderson, K. A., Bialeschki, M. D., Scanlin, M. M., Thurber, C. A., Whitaker, L. S., \& Marsh, P. E. (2007). Components of camp experiences for positive youth development. Journal of Youth Development, $1(3), 1-12$.

Henderson, K. A., Whitaker, L. S., Scanlin, M. M., \& Thurber, C. (2007). Summer camp experiences: Parental perceptions of youth development outcomes. Journal of Family Issues, 28(8), 987-1007. doi:10.1177/0192513X07301428

Knapp, D., Devine, M. A., Dawson, S., \& Piatt, J. (2015). Examining perceptions of social acceptance and quality of life of pediatric campers with physical disabilities. Children's Health Care, 44(1), 1-16. doi:10.1080/02739615.2013.870041

Martilla, J. A., \& James, J. C. (1977). Importance-performance analysis. Journal of Marketing, 41(1), 7779.

McLaughlin, J. A., \& Jordan, G. B. (2010). Using logic models. In J. S. Wholey, H. P. Hatry, \& K. E. Newcomer (Eds.), Handbook of practical program evaluation ( $3^{\text {rd }}$ ed., pp. 55-80). San Francisco, CA: Jossey-Bass.

Miles, M. B., Huberman, A. M., \& Saldaña, J. (2014). Qualitative data analysis: A methods sourcebook (3 ${ }^{\text {rd }}$ ed.). Thousand Oaks, CA: Sage.

Nagaoka, J., Farrington, C. A., Ehrlich, S. B., \& Heath, R. D. (2015). Foundations for young adult success: A development framework. Chicago, IL: University of Chicago, Consortium on School Research. Retrieved from https://consortium.uchicago.edu/sites/default/files/publications/Wallace Report.pdf

Olsen, L. K.-P., Powell, G. M., Garst, B. A., \& Bixler, R. D. (2018). Camp and college parallels: Crucibles for transition-linked turning-points. Journal of Youth Development, 13(1-2), 126-143. doi:10.5195/jyd.2018.558

Putnam, R. D. (2015). Our kids: The American dream in crisis. New York, NY: Simon \& Schuster.

Richmond, D., Sibthorp, J., Gookin, J., Annarella, S., \& Ferri, S. (2018). Complementing classroom learning through outdoor adventure education: Out-of-school-time experiences that make a difference. Journal of Adventure Education and Outdoor Learning, 18(1), 36-52. doi:10.1080/14729679.2017.1324313

Shechtman, N., DeBarger, A. H., Dornsife, C., Rosier, S., \& Yarnall, L. (2013). Promoting grit, tenacity, and perseverance: Critical factors for success in the $21^{\text {st }}$ century. Washington, DC: U.S. Department of Education.

Sibthorp, J., Browne, L. P., \& Bialeschki, M. D. (2010). Measuring positive youth development at summer camp: Problem solving and camp connectedness. Research in Outdoor Education, 10, 1-12. 
Camp's Role in Developing Long-Term Outcomes

U.S. Census Bureau. (2019). Quick facts: United States. Retrieved from https://www.census.gov/quickfacts/fact/table/US/PST045218

Vandell, D. L., Larson, R. W., Mahoney, J. L., \& Watts, T. W. (2015). Children's organized activities. Handbook of child psychology and developmental science (vol 4, $7^{\text {th }}$ ed.). Washington, DC: Committee on Community-Level Programs for Youth. Board on Children, Youth, and Families, Division of Behavioral and Social Science and Education. doi:10.1002/9781118963418.childpsy408

Wells, M. S., \& Arthur-Banning, S. G. (2008). The logic of youth development: Constructing a logic model of youth development through sport. Journal of Park \& Recreation Administration, 26(2), 189202.

Whittington, A., \& Garst, B. A. (2018). The role of camp in shaping college readiness and building a pathway to the future for camp alumni. Journal of Youth Development, 13(1-2), 105-125. doi:10.5195/JYD.2018.519

Wilson, C., Akiva, T., Sibthorp, J., \& Browne, L. P. (2019). Fostering distinct and transferable learning via summer camp. Children and Youth Services Review, 98(January), 269-277. doi:10.1016/j.childyouth.2019.01.017

Wilson, C., \& Sibthorp, J. (2018). Examining the role of summer camps in developing academic and workplace readiness. Journal of Youth Development, 13(1-2), 83-104. doi:10.5195/JYD.2018.563

Yuen, F. C., Pedlar, A., \& Mannell, R. C. (2005). Building community and social capital through children's leisure in the context of an international camp. Journal of Leisure Research, 374), 494-518. 